\title{
Association of silicosis, lung dysfunction, and emphysema in gold miners
}

\author{
R L Cowie, M Hay, R Glyn Thomas
}

\begin{abstract}
Background-In an earlier study of gold miners men with silicosis were found to have abnormal lung function, including airflow obstruction and reduced diffusing capacity. In a follow up study a sample of these men was examined by computed tomography to determine whether emphysema accounted for these abnormalities, which are associated with silicosis in this working population.
\end{abstract}

Methods-A sample of 70 men from a cohort of older gold miners with and without silicosis who had worked underground for a mean period of 29 years was examined by computed tomography to determine whether each man had emphysema. In addition, each man had lung function tests and routine chest radiography $(125 \mathrm{kV})$.

Results-A total of 48 men had emphysema on examination by computed tomography. On the basis of the results in a chest radiograph 55 of the men had silicosis. Emphysema was related to silicosis, being present in five of the 15 men without silicosis and in 43 of the 55 with silicosis. Diffuse emphysema was apparent in two men without silicosis (14\%) and in 25 men with silicosis (45\%). The proportion of men with diffuse emphysema increased from $14 \%$ in those with International Labour Organisation category 0 nodule profusion to $46 \%$ in those with category $1,48 \%$ in those with category 2 , and $67 \%$ in those with category 3 . Emphysema was also related to smoking: eight of the 18 who had never smoked and 40 of the 52 smokers had emphysema. All of those who had never smoked and had emphysema had silicosis with category $2 / 2$ or greater nodule profusion. Lung function tests showed changes associated with silicosis that could be explained by the associated emphysema. Conclusions-In this population emphysema occurred in association with silicosis and accounted for the abnormalities in lung function associated with silicosis.

(Thorax 1993;48:746-749)

In a working population of gold miners silicosis was associated with abnormal lung func- tion after the effects of dust exposure and smoking were controlled for. ${ }^{1}$ Koskinen has $\overrightarrow{0}$ reported similar findings in subjects with silicosis, ${ }^{2}$ but in other studies little or no abnormal lung function has been attributed to chronic, simple silicosis. ${ }^{34}$ An association between chronic silicosis and emphysema might explain these changes in lung function. Results are conflicting on the association of between emphysema and uncomplicated 0 silicosis. ${ }^{56}$

Computed tomography of the lungs has been used to evaluate pneumoconiosis and emphysema in men who have been occupa- $\bar{c}$ tionally exposed to dust containing silica. ${ }^{7-9}$ The purpose of this study was to examine a group of older gold miners for emphysema and to determine the sensitivity of computed tomography in detecting silicosis.

\section{Methods}

The men who were studied were members of a cohort of older gold miners with and without silicosis who were participating in a follow up evaluation four to five years after their entry to the cohort and initial evaluation. The men who were examined by computed tomography of the chest were randomly selected from those who attended for interview, lung function tests, and chest radiography. The selection was determined by sending the first three of the 10 men examined each day for computed tomography. The order in which the men were examined was $N$ not determined by any personal or occupa- $N$ tional characteristics. The investigator who N interviewed each man and performed the 0 lung function tests did not determine the order in which the men were examined and $\frac{D}{\mathbb{D}}$ had no knowledge of the radiological status of $\stackrel{\oplus}{?}$ each subject. The radiologists who examined $T$ the computed tomograms had no access to $\frac{\vec{D}}{D}$ the chest radiographs or to any other data on $\stackrel{\square}{\stackrel{\oplus}{9}}$ the subjects other than the knowledge that $\stackrel{\mathbb{Q}}{\Omega}$ they were part of the study cohort.

Before computed tomography, each man $\varnothing$ was interviewed using a short occupational and respiratory questionnaire. Lung function tests including a forced expiratory flow-vol- $\underset{?}{?}$ ume loop and single breath lung diffusion were performed according to American Thoracic Society standards ${ }^{10}$ using a Morgan Transfertest Model A incorporating a dry rolling seal spirometer of 8 litres and a flow- 
volume differentiator (PK Morgan, Chatham, Kent) linked to a Medical Graphics analogue digital convertor (Medical Graphics, St Paul, Minnesota) and an Apple 2e computer with Medical Graphics operating software. Each man then had taken a full size, posteroanterior chest radiograph $(125 \mathrm{kV})$, which was read independently by two readers, neither of whom read the computed tomograms and without reference to previous films, lung function results, or information on occupation or symptoms.

The reading of the chest radiograph according to International Labour Organisation guidelines ${ }^{11}$ defined nodule profusion for the study. Silicosis was defined as nodule profusion greater than $0 / 1$ on the standard $125 \mathrm{kV}$ posteroanterior chest film.

The lung computed tomograms were produced by a Siemens Somotom DR-G CT scanner with the subjects supine. From an anteroposterior topogram six evenly spaced tomographic slices (2 $\mathrm{mm}$ thick) were obtained during full inspiration. The first slice was obtained at the lung apices and the last immediately above the domes of the diaphragm. Thus two tomographic slices 2 $\mathrm{mm}$ wide were obtained through each of the upper, middle, and lower zones of the lungs. A scan time of 3 seconds was used to minimise movement artefact. The images were obtained at $125 \mathrm{kV}$ and 230 mas. All images were stored on floppy disks for subsequent evaluation at the console using a window width of 1000 and a window centre of -700 .

Computed tomographic readings for small nodules were classified into four categories: category 0 when no nodules were seen, category 1 when a few nodules were seen, category 3 when innumerable nodules were seen, and category 2 when an intermediate number of nodules was seen. For the purpose of designating a nodule category the lungs were divided into upper, middle, and lower zones and right and left sides, giving six zones. The category of profusion was determined by the overall distribution in the manner suggested by the International Labour Organisation ${ }^{11}$ for the reading of plain chest radiographs.

Computed tomographic findings for emphysema were based on techniques and criteria that have been validated. ${ }^{12-14}$ Emphysema was considered to be present when areas of abnormally low attenuation were identified as determined visually or where obvious bullae were detected at examination. All six slices were assessed for emphysematous change, which was then graded according to the percentage of the overall area affected. When no emphysematous changes were noted the subject was classified as having grade 0 emphysema. Grade 1 emphysema was recorded when emphysema was present but affected less than $25 \%$ of the lung, grade 2 when emphysema affected $25 \%-50 \%$, grade 3 when $50 \%-75 \%$, and grade 4 when more than $75 \%$ of the lung was affected. Emphysema was also categorised as being diffuse or focal.

The data were analysed by univariate analysis using Fisher's exact test and $\chi^{2}$ analysis of categorical data and by Student's $t$ test and analysis of variance ${ }^{15}$ for continuous variables. Analysis with multiple independent variables was performed by multiple linear regression. ${ }^{15}$

\section{Results}

Of the original 1197 men who entered the cohort by participating in a cross sectional study during $1984-5,950$ men (79\%) were working in the mines in January 1989. A group of 267 men selected randomly after stratification according to their original category of nodule profusion was invited to participate in the follow up study; $242(91 \%)$ attended. From those 242 men 70 were randomly selected to have lung computed tomography. These 70 men did not differ in any relevant characteristic from the whole follow up group of 242 men or, for the information available, from the 951 men from the original cohort who were still working. The mean (SD) age of those with computed tomograms was 49.7 years $(5.92$ years), that of the whole follow up group of $242,49.9$ years (5.78 years), and that of the $951 \mathrm{mem}$ bers of the cohort who were still working 49.9 years (6.35 years). The men in the subgroup who had computed tomograms had worked underground in gold mines for a mean 29.6 years ( 7.76 years), the 242 men in the follow up group for 29.3 years (6.72 years) and the 951 men in the cohort who were still working for $29 \cdot 1$ years (6.98 years). Eighteen (26\%) men in the computed tomography group and $50(21 \%)$ in the whole group had never smoked.

Fifteen of the 70 subjects in the computed tomography group and 41 in the whole follow up group did not have silicosis $\left(\chi_{2}=0.74\right.$, $\mathrm{p}=0.4$ ). Fifteen of the 55 men with silicosis had category 1,34 category 2 , and six category 3 nodule profusion determined by the examination of their posteroanterior chest radiographs. Included in the men with silicosis were 13 with large opacities, 11 with opacities classified according to the International Labour Organisation's standard guidelines as category A (10 to $50 \mathrm{~mm}$ ) and one each with opacities classified as category $\mathbf{B}$ and category $\mathrm{C}$.

In six cases the computed tomograms had not been stored on a floppy disk and the hard copies of these scans were examined with a magnifying glass. The category of nodule profusion by computed tomography agreed with that from the chest radiograph in 37 of the 70 subjects, was higher in three, and lower in 30 of the subjects. Table 1 shows the comparison between the computed tomographic findings and chest radiology of nodule profusion.

By computed tomography emphysema was judged to be present in 48 men. In 38 the emphysema affected less than $25 \%$ of the lung and in 10 more than $25 \%$ but less than $50 \%$ of the lung. No subject had emphysema affecting more than $50 \%$ of the lung. The presence of emphysema was associated with 
Table 1 Comparison of silicotic nodule profusion assessed by chest radiology and computed tomography

\begin{tabular}{llrcr}
\hline $\begin{array}{l}\text { Radiological } \\
\text { nodule }\end{array}$ & \multicolumn{4}{l}{ Tomographic nodule profusion } \\
\cline { 2 - 5 } profusion & 0 & 1 & 2 & 3 \\
\hline 0 & 13 & 1 & 1 & \\
1 & 5 & 9 & 1 & \\
2 & 4 & 16 & 14 & 1 \\
3 & & 4 & 1 & 1 \\
\hline
\end{tabular}

The reading of the radiographs and computed tomograms were in agreement in 37 of the 70 subjects (53\%) (Tau $\mathrm{b}=0.523$, ASE 0.081 , Spearman correlation 0.582 , ASE 0.087 ). The computed tomographic readings for nodule profusion were lower than the radiological readings in 30 subjects and higher in three.

silicosis: five of the 15 men without silicosis and 43 of the 55 men with silicosis had emphysema ( $p=0.002$, Fisher's exact two tail test). Ten of the 13 men with large opacities $(77 \%)$ had emphysema. When the computed tomographic assessment of nodule profusion was used, the relation between silicosis and emphysema persisted, nine out of 22 men without computed tomographic evidence of silicosis having emphysema and 39 of the 48 men with silicosis $(p<0.002$, Fisher's). In the 64 men whose computed tomograms had been stored for rescreening and reading by two radiologists, 27 were judged to have diffuse emphysema as opposed to focal changes. The association of diffuse emphysema with silicosis was maintained, with $14 \%$ of the men without silicosis and $50 \%$ of the men with silicosis having diffuse emphysema ( $p<0.02$, Fisher's). The percentage of men with diffuse emphysema increased from $14 \%$ in those without silicosis to $46 \%$ in those with category 1 nodule profusion, $48 \%$ with category 2 , and $67 \%$ with category 3 nodule profusion. Fewer men who had never smoked $(8 / 18)$ had emphysema compared with smokers $(40 / 52) \quad(p<0.02$ Fisher's). Two of the eight with emphysema who had never smoked had large opacities and grade 2 emphysema. The remaining six with emphysema had silicosis with $2 / 2$ or greater nodule profusion. The smokers with emphysema had smoked a mean (SD) of 11.8 (6.72) pack years, which did not differ significantly from the $8.8(5.04)$ pack years smoked by the smokers without emphysema

Table 2 Emphysema, lung function, dust exposure, and silicosis. Values are means (SD)

\begin{tabular}{|c|c|c|c|c|c|}
\hline & \multicolumn{3}{|c|}{ Grade of emphysema } & \multirow[b]{2}{*}{$F(d f=2)$} & \multirow[b]{2}{*}{$p$} \\
\hline & $0(n=22)$ & $1(n=38)$ & $2(n=10)$ & & \\
\hline FVC (\% predicted $)^{16}$ & $96 \cdot 8(11 \cdot 13)$ & $95.4(15.48)$ & $90.5(13.31)$ & 0.7 & NS \\
\hline $\mathrm{FEV}_{1}$ (\% predicted) ${ }^{16}$ & $94 \cdot 1(8 \cdot 87)$ & $86.5(16.09)$ & $68 \cdot 0(12 \cdot 15)$ & $12 \cdot 5$ & 0.0001 \\
\hline $\mathrm{FEV}_{1} / \mathrm{FVC}(\%)$ & $80(6 \cdot 4)$ & $76(9 \cdot 0)$ & $63(9 \cdot 3)$ & $115 \cdot 0$ & 0.0001 \\
\hline MMEF (\% predicted) ${ }^{16}$ & $85 \cdot 8(27 \cdot 76)$ & $69.8(29.41)$ & $34 \cdot 1(16 \cdot 13)$ & $12 \cdot 2$ & 0.0001 \\
\hline TLCo (\% predicted $)^{16}$ & $106 \cdot 1(18 \cdot 48)$ & $91.5(19.40)$ & $81.6(19.64)$ & $6 \cdot 8$ & 0.002 \\
\hline Silicosis $\dagger$ & $4 \cdot 2(2 \cdot 70)$ & $5.9(2.41)$ & $6.9(1.52)$ & $5 \cdot 6$ & 0.006 \\
\hline Years underground & $30(7 \cdot 7)$ & $30(8 \cdot 2)$ & $29(6 \cdot 5)$ & $0 \cdot 1$ & NS \\
\hline Pack years $\ddagger$ & $4 \cdot 5(5 \cdot 84)$ & $10 \cdot 2(7 \cdot 47)$ & $8 \cdot 2(6 \cdot 81)$ & $4 \cdot 75$ & 0.01 \\
\hline
\end{tabular}

$0=$ No emphysema, $1=$ less than $25 \%$ of lung affected, $2=25-50 \%$ of lung affected †Category of nodule profusion with 1 equivalent to International Labour Organisation $0 / 0$ and 10 to $3 / 3 .{ }^{11} \ddagger$ Summary of smoking history.
$(\mathrm{T}=1 \cdot 64, \mathrm{p}>0 \cdot 1)$. Twelve of the 18 who had never smoked and 43 of the 52 smokers had silicosis ( $p>0 \cdot 1$, Fisher's exact test). There was no significant difference in the duration of exposure to the underground environment in the men with emphysema $(29.6(7 \cdot 89)$ years) and those without emphysema $(29.6(7 \cdot 71)$ years).

The presence of silicosis was associated $\stackrel{\overrightarrow{0}}{x}$ with reductions in the forced expiratory volume in one second $\left(\mathrm{FEV}_{1}\right)(\mathrm{p}<0.05)$, $\stackrel{?}{+}$ $\mathrm{FEV}_{1} /$ forced vital capacity (FVC) $(\mathrm{p}<0.05)$, maximal mid-expiratory flow rate (MMEF) $(p<0.005)$, and single breath lung carbon monoxide transfer factor (TLCO) $(\mathrm{p}<0.05)$. After smoking and duration of work underground was controlled for, silicosis retained a $\overrightarrow{0}$ significant association with reductions of $\overrightarrow{\vec{\omega}}$ $\mathrm{FEV}_{1} / \mathrm{FVC}$ and MMEF. However, after the $\vec{\omega}$ presence and grade of emphysema was con- $\overrightarrow{\vec{*}}$ trolled for no association between lung func- $x$ tion and silicosis remained. The presence of $\stackrel{\infty}{\oplus}$ emphysema was associated with reductions in $\mathrm{FEV}_{1}(\mathrm{p}<0.0001), \mathrm{FEV}_{1} / \mathrm{FVC}(\mathrm{p}<0.001)$, के MMEF $(p<0.001)$ and TLCo $(p<0.01)$ 웅 after silicosis, years worked underground, and $\rightarrow$ smoking were controlled for. Table 2 shows $\subseteq$ the data on lung function, exposure to dust, and smoking.

\section{Discussion}

In an earlier study of the same population of men working underground in gold mines a relation between the presence and degree of $\stackrel{\mathbb{Q}}{\square}$ simple, chronic silicosis and airflow limitation $\overrightarrow{\overrightarrow{0}}$ was noted. ${ }^{1}$ This finding persisted after smok- 3 ing and the duration of exposure to the underground working environment were controlled for, both factors having been associated with airflow limitation. In our current study a random sample of the cohort formed $x$ by participation in the initial cross sectional $\frac{0}{3}$ study was examined by lung computed tomography. We found an association $\frac{\circ}{3}$ between silicosis and emphysema and that the lung dysfunction associated with silicosis seems to be caused by the associated emphy- $\frac{7}{0}$ sema. Other investigators have shown no significant association between silicosis and $\mathcal{N}$ emphysema, ${ }^{59}$ but a recent post mortem $N$ study of South African gold miners showed N an association between silicosis and emphysema. ${ }^{6}$ No lung function data were presented ${ }_{0}$ in that study, but in an earlier study of lung $\stackrel{\varnothing}{\Phi}$ function and chest radiography in the same $\stackrel{?}{+}$ population of gold miners no lung dysfunc- $T$ tion was attributable to silicosis after expo- $\frac{\vec{D}}{\vec{D}}$

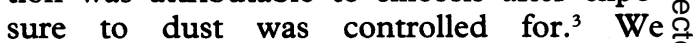
previously alluded to differences between the $\stackrel{\mathbb{Q}}{\Omega}$ white gold miners in that study and the black gold miners in our study and suggested that $\delta$ this might reflect differences in intensity of exposure between those who supervise and those who work in this labour intensive? industry.

The evaluation of silicosis by computed tomography seemed to be less sensitive than that by conventional chest radiology. This has been noted by others ${ }^{7}$ and is particularly true 
for thin section computed tomography, ${ }^{17}$ as might be expected if one considers the bulk of lung included in a chest radiograph compared with that in a single cut on thin section computed tomography. A contrary finding in a recent paper is difficult to explain: also difficult to explain was the apparently better lung function (significant for MMEF) of the subjects in that study with silicosis than those without silicosis on thin section CT. ${ }^{18}$ In that respect their findings differ from ours and from those of an earlier study by their group. ${ }^{19}$ This might indicate that the subjects and their disorder in their later study differ from the subjects and silicosis in our study.

In our current study the computed tomographic assessments had a low agreement with radiological results in determining the presence of silicosis. Computed tomography failed to identify silicotic nodules in nine of the 55 men considered to have silicosis in a radiograph and identified nodules in two of the 15 men with no silicosis in a chest radiograph.

We were not able to determine whether silicosis causes emphysema or whether both have a similar origin from exposure to the underground mine environment, including respirable particles of dust containing silica. In these men, however, silicosis is a marker, visible on conventional radiography, for emphysema and for lung dysfunction in excess of that found in men from the same working environment who do not have silicosis.

We thank Dr Brian Brink and the management of the Ernest Oppenheimer Hospital for allowing us to use the hospital facilities to do the study; $\mathbf{M r}$ Salmon Mabena who interviewed the subjects and did the lung function tests; and Dr Mike van Schalkwyk who was the second reader of the chest radiographs.
1 Cowie RL, Mabena SK. Silicosis, chronic airflow limitation, and chronic bronchitis in South Africa gold miners. Am Rev Respir Dis 1991;143:80-4.

2 Koskinen $\mathrm{H}$. Symptoms and clinical findings in patients with silicosis. Scand $\mathcal{F}$ Work Environ Health 1985;11: 101-6.

3 Irwig LM, Rocks P. Lung function and respiratory symptoms in silicotic and non-silicotic gold miners. Am Rev Respir Dis 1978;117:429-35.

4 Ziskind M, Jones RN, Weill H. Silicosis. Am Rev Respir Dis 1976;113:643-65.

5 Becklake MR, Irwig L, Kielkowski D, Webster I, De Beer M, Landau S. The predictors of emphysema in South African gold miners. Am Rev Respir Dis 1987;135: $1234-41$.

6 Hnizdo E, Sluis-Cremer GK, Abramowitz JA. Emphysema type in relation to silica dust exposure in South African gold miners. Am Rev Respir Dis 1991;143:1241-7.

7 Müller NL, Miller RR. Computed tomography of chronic diffuse infiltrative lung disease. Part 2. Am Rev Respir Dis 1990;142:1440-8.

8 Bergin CJ, Müller NL, Vedal S, Chan-Yeung M. CT in silicosis: correlation with plain films and pulmonary function tests. AfR Am f Roentgenol 1986;146:477-83.

9 Kinsella M, Müller NL, Vedal S, Staples C, Abboud RT, Chan-Yeung M. Emphysema in silicosis. Am Rev Respir Dis 1990;141:1497-500.

10 Ferris BG. Epidemiology standardization project. Am Rev Respir Dis 1978;118:1-120.

11 International Labour Office. Guidelines for the use of ILO international classification of radiographs of pneumoconioses. Geneva: International Labour Office, 1980.

12 Bergin C, Müller N, Nichols DM, Lillington G, Hogg JC, Mullen B, et al. The diagnosis of emphysema: a computed tomographic-pathological correlation. Am Rev Respir Dis 1986;133:541-6.

13 Sanders C, Nath PH, Bailey WC. Detection of emphysema with computed tomography: correlation with pulmonary function tests and chest radiography. Invest Radiol 1988;23:262-6.

14 Goddard PR, Nicholson EM, Laszlo G, Watt I. Computed tomography in pulmonary emphysema. Clin Radiol 1982;33:379-87.

15 SAS Institute $S A S / S T A T$ guide for personal computers. Version 6 ed. Cary, North Carolina: SAS Institute, 1985.

16 American Thoracic Society. Evaluation of impairment/disability secondary to respiratory disorders. Am Rev Respir Dis 1986;133:1205-9.

17 Mathieson JR, Mayo JR, Staples CA, Müller NL. Chronic diffuse infiltrative lung disease: comparison of diagnostic accuracy of CT and chest radiography. Radiology 1989;171:111-6.

18 Bégin R, Ostiguy G, Fillion R, Colman N. Computed tomography scan in the early detection of silicosis. $\mathrm{Am}$ Rev Respir Dis 1991;144:697-705.

19 Bégin R, Ostiguy G, Cantin A, Begeron D. Lung function in silica-exposed workers: a relationship to disease severity assessed by CT scan. Chest 1988;94:539-45. 